Western University

Scholarship@Western

FIMS Publications

Information \& Media Studies (FIMS) Faculty

$5-2006$

\title{
The Seeking of Baby-Feeding Information by Canadian Women Pregnant with Twins
}

Pamela J. McKenzie

University of Western Ontario, pmckenzi@uwo.ca

Follow this and additional works at: https://ir.lib.uwo.ca/fimspub

Part of the Library and Information Science Commons

Citation of this paper:

McKenzie, Pamela J., "The Seeking of Baby-Feeding Information by Canadian Women Pregnant with Twins" (2006). FIMS

Publications. 48.

https://ir.lib.uwo.ca/fimspub/48 


\section{THE SEEKING OF BABY-FEEDING INFORMATION BY CANADIAN WOMEN}

PREGNANT WITH TWINS [uncorrected proof; corrected proof posted to Midwifery website

of forthcoming papers, 2006.05.11]

Pamela J. McKenzie, BA, MA, MLIS, PhD

Assistant Professor,

Faculty of Information and Media Studies,

The University of Western Ontario,

London, Ontario N6A 5B7.

Telephone 1-519-661-2111 ex.88514;

Fax 1-519-661-3506;

E-mail:pmckenzi@uwo.ca. 


\title{
THE SEEKING OF BABY-FEEDING INFORMATION BY CANADIAN WOMEN PREGNANT WITH TWINS
}

KEYWORDS: (CINAHL) Infant Feeding; Information Seeking Behavior; Pregnancy, Multiple; Qualitative Studies

\begin{abstract}
Objective: to analyse baby-feeding information needs and seeking described by Canadian women pregnant with twins.
\end{abstract}

Design, setting, and participants: in-depth semi-structured interviews with 19 pregnant women were audio-recorded and transcribed verbatim. Transcripts provided the data for discourse analysis of the use of two interpretative repertoires.

Measurements and findings: the first interpretative repertoire represented caring for twins as fundamentally distinct from caring for singly-born children and therefore emphasised the commonality of mothers of twins regardless of their background or situation. The second highlighted the uniqueness and individuality of each person. These repertoires intersect with discourses of baby- feeding and good mothering, resulting in a complex discursive interplay of similarity and difference, commonality and individuality, information seeking, baby-feeding and good mothering. Participants used the two interpretative repertoires to a) frame information needs; b) construct complex accounts of the biomedical, experiential, and personalised authority of information sources, c) describe the helpfulness of information sources independent of their authority; and d) describe the barriers encountered in the finding appropriate sources of babyfeeding information antenatally. 
Implications: understanding and respecting the discursive constructions of pregnancy and mothering can help practitioners understand the complex discursive interplay underlying participants' baby-feeding decisions and may facilitate more sensitive support for women's individual needs and understandings. 
Information seeking in multiple pregnancy/1

\section{INTRODUCTION}

It has been argued that getting and giving information is the fundamental function of antenatal care (Browner and Press 1997). Researchers in several health and social science disciplines have studied pregnant women as seekers of information in general (for example, Aaronsen et al 1988, Freda et al. 1993, McKenzie 2003a) and of information about baby-feeding in particular (Britton 1998, Chezem et al 2001). Studies have considered the role of ante- and perinatal baby-feeding information resources such as peer support providers (Schafer et al 1998, Vari et al 2000), antenatal classes (Lowe 1998, Sheehan 1999), and health care providers (e.g., Rajan 1993, Howard et al 1997, Izatt 1997, Hoddinott and Pill 2000).

Although women may make baby-feeding decisions either prior to conception or very early in pregnancy (Earle 2000), the diagnosis of a multiple pregnancy may involve revisiting and perhaps revising an initial baby-feeding decision as a pregnant woman accommodates the new reality in her life (Van der Zalm 1995, Beck 2002a). Surveys of women pregnant with twins have identified baby-feeding as a topic about which these women express a need for information (Malmstrom and Biale 1990, Launslager 1994, Nys et al. 1998). As multiple birth rates have begun to climb (Blondel and Kaminski 2002), the additional physical and psychological demands of multiple pregnancy and parenting have received the attention of researchers and practitioners alike (Thorpe et al 1995, Bowers 1998, Mariano and Hickey 1998, Beck 2002b). There is, however, little research about the baby-feeding information needs and information seeking of women pregnant with multiples. The published literature on the feeding of infant multiples consists mainly of breast-feeding case reports (e.g., Auer and Gromada 1998) and guidelines for 
Information seeking in multiple pregnancy/2

professionals supporting breast-feeding mothers (e.g., Gromada and Spangler 1998, Hattori and Hattori 1999, Moxley and Haddon 1999). Recent studies of breast-feeding decision-making, initiation and duration either do not mention the needs of women with multiple gestations (e.g., Earle 2000) or explicitly exclude them (e.g., Sheehan et al. 2001, Dennis et al. 2002). This article fills this gap by analysing the baby-feeding information needs of Canadian women pregnant with twins and seeks to contribute to the literature 'describing and theorising the complexity of women's breast-feeding experiences' (Sheehan et al 2003, p266).

\section{METHODS}

\section{Research design}

Data analysed here were collected in 1999 and 2000 as part of a larger study of the information needs and seeking of 19 women pregnant with twins, living in southern Ontario, Canada, and fluent in English. Because the number of women pregnant with multiples at any given time is quite small, this study, like other studies of this population (e.g., Van der Zalm 1995), used a convenience sample. To maximize the variability of the sample, recruitment strategies were designed to reach as wide a variety of potential participants as possible (Van der Zalm 1995). I sought and received permission to recruit participants through contacts with health care providers and a parent organization. Five participants contacted me after reading flyers placed in obstetrical office waiting areas. Two agreed to participate after speaking with me at the local public health unit's fairs for women in early pregnancy. I recruited two participants at meetings of the local Multiple Births Canada parent support group. Advertisements in local newspapers 
Information seeking in multiple pregnancy/3 and flyers in local shops attracted an additional seven participants, and the remaining three were referred by mutual acquaintances. This research conforms to the Social Science and Humanities Research Council of Canada's guidelines on research with human subjects and passed an ethical review at The University of Western Ontario and the local health unit. All participants gave their informed consent, and in order to protect confidentiality participants are identified with pseudonyms throughout.

The research design was naturalistic (Lincoln and Guba 1985). I conducted, audio tape-recorded, and fully transcribed 19 initial and 17 follow-up interviews (two of the women participating in the initial interview withdrew from the study after going into premature labour). In addition, detailed field notes were recorded as soon as possible after each interview. Repeated interviewing facilitated the processes of constant comparison (Glaser and Strauss 1967) of instances across participants, and facilitated both prolonged engagement and member checking, as later participants were asked to reflect on, further develop, or validate themes that had arisen in interviews with previous participants (Lincoln and Guba 1985). My own experience as a mother of twins and a former peer breast feeding counsellor enabled me to learn the context and to build trust with participants, and peer debriefing and member-checking assisted in the maintenance of a sense of 'detached wonder' Lincoln and Guba $(1985,304)$ in a familiar setting.

Data interpretation has been idiographic, striving to find patterns rather than causes and effects, and findings are recognized to be context-dependent and are applied tentatively. Naturalistic inquiry demands that the number of cases be sufficient to develop analytical concepts and 
Information seeking in multiple pregnancy/4 categories, rather than cases, to the point of redundancy or saturation (Strauss and Corbin 1990, 177, Erlandson et al., 1993, 83). Systematic scanning of data revealed no new themes or concepts after 16 participants. Saturation was confirmed as interviews with three additional participants yielded no additional new themes.

\section{Data collection}

Researchers conducting naturalistic inquiry accept that realities are multiple, constructed, and holistic (Lincoln and Guba 1985, 36-8, Erlandson 1993). In-depth interviews are an appropriate method for eliciting participant's own perspectives and stories, and interview transcripts provide rich sources of data for discourse analysis (Potter and Wetherell 1987).

The semi-structured initial interviews (ranging from 25 to 110 minutes long) began with a 'grand tour' question concerning the impact of multiple pregnancy on the woman's life. The remaining questions were derived from the goals of the larger study and were designed to elicit respondents' accounts of their information needs and seeking related to their pregnancies. Questions addressed women's significant concerns and invited their accounts of seeking, encountering, or receiving advice or information about any aspect of their multiple pregnancies, births, or forthcoming motherhood. The follow-up interviews ranged from 6.5 to 74 minutes long. They clarified questions arising from the initial interviews and addressed any information needs that had arisen for the woman in the week to 15 days since the initial interview. Follow-up questions therefore varied from participant to participant and were developed following transcription and preliminary analysis of the initial interview. All interviews took place in locations chosen by 
Information seeking in multiple pregnancy/5

participants (women's homes or workplaces, or the local public library). One follow-up interview was conducted by telephone as the participant moved house between the initial interview and the follow-up.

\section{Data analysis}

Interview transcripts were open-coded (Strauss and Corbin 1990) and The Ethnograph 5.0

(Seidel 1998) was used to gather together the 52 mentions of baby-feeding in the interview transcripts for analysis. Data analysis is based on the discourse analysis of Potter and Wetherell (1987), which draws variously from conversation analytic, ethnomethodological, and poststructural theoretical traditions to analyse the ways that discourse is constructed and the rhetorical functions it is meant to perform (Potter 1996). Rather than viewing discourse as an indicator of 'below the surface' processes or indicators such as attitudes and beliefs, such an analysis considers the discourse itself (ie, the participant's account) to be the site of interesting processes and is therefore an ideal method for studying the kinds of claims that individuals make to convince a reader or listener of the authority or helpfulness of an information source. Data analysis requires a close study of the variations in the ways discourse is constructed within and across accounts in order to derive an understanding of the functions that an account might be serving and the specific discursive components used to construct the versions.

The specific analytic practices of discourse analysis (Potter and Wetherell 1987) include:

- paying close attention to the details of language use by examining transcripts or written texts rather than numerical summaries or remembered notes of interactions 
Information seeking in multiple pregnancy/6

- focussing on the discourse itself as the primary object of research rather than as a transparent medium revealing the true nature of an individual's attitudes and beliefs, or the true nature of events

- making a close study of variations in the ways discourse is constructed, both within and across accounts, in order to derive some understanding of the functions that discourse might be serving and the ways it is constructed.

The fundamental unit of analysis is the interpretative repertoire (Potter and Wetherell 1987 p172), a discursive building block which is a restricted range of terms used in a specific stylistic and grammatical fashion. In describing the characteristics of multiple pregnancy and parenting, pregnant women used two major interpretative repertoires. The first emphasised the distinctiveness of multiple (as opposed to singleton) pregnancy and parenting, while the second was constructed around the uniqueness and individuality of each person, both each individual pregnant woman and each of her unborn babies. These interpretative repertoires can be seen as the underlying stories told about twin pregnancy, birth, and motherhood by pregnant women.

Analysis of accounts of baby-feeding focusses on the ways that participants used these interpretative repertoires in conversation to a) frame information needs, b) construct complex accounts of the biomedical, experiential, and personalised authority of information sources, c) describe the helpfulness of information sources independent of their authority; and d) describe the barriers encountered in the course of seeking baby-feeding information. 
Information seeking in multiple pregnancy/7

\section{FINDINGS AND DISCUSSION}

Several limitations of this study should be noted. First, participants were not followed postpartum so actual baby-feeding practices are unknown. Second, findings from this small scale qualitative study should not be generalised to other populations. This article rather shares with Earle the aim 'to provide an insight into perceptions and experiences of baby feeding, but it does not claim to represent the experiences of all women' (Earle 2000, p324). Third, baby-feeding was not the focus of the larger study and the interview schedule therefore did not contain specific questions about feeding. Eighteen of the 19 participants discussed baby-feeding during the interviews, and seven of these identified baby-feeding as the most significant concern they have had since finding out they were carrying twins. The interview data should therefore be treated, not as a consistently administered survey of baby-feeding attitudes, but rather as an example of the ways that baby-feeding may naturally come up and be discussed in a conversation. This limitation is in fact an advantage in cases such as this where the topic of discussion is valueladen and potentially problematic for participants. Other researchers have considered it analytically preferable not to ask directly about a topic but rather to analyse examples occurring naturally in a conversation (Wetherell and Potter 1992, 98-99).

\section{Characteristics of participants}

Participants' first language spoken, ethnicity, and urban or rural place of residence were representative of the region in which they lived. Ranging from 19 to 40 years old, they tended to be older and better educated than the general population of childbearing women in the province 
Information seeking in multiple pregnancy/8

of Ontario (Statistics Canada, Health Statistics Division 2001). Although one participant had not completed high school, 15 of the 19 had completed some post-secondary education, 10 had undergraduate university degrees, and 4 had master's degrees. All were living with the fathers of their babies, and 16 of the 19 were married. Thirteen were primiparas and the 6 multiparas had between 1 and 3 children each. Four participants were unemployed or at home with other children. The others had part- or full-time jobs in a range of occupations, from clerical, industrial and food service to library, health care, and education. Participants ranged from 11 to 35 weeks gestation, and the multiple pregnancy had been diagnosed between 1 and 21 weeks previous. Of the 18 participants discussing baby-feeding, one intended to bottle feed from the outset, 15 intended to begin with exclusive breast-feeding, one intended to breast feed one baby and bottle feed the other, switching babies with each feed, and one was not sure. It is notable that no participant said she was 'assuming I'll breast feed' twins, and all except the committed bottlefeeder described a need to 'play it by ear' (Sheehan et al 2003).

\section{Information-seeking, breast-feeding, and good mothering}

It has been argued that many women, reacting to popular literature and media representations, feel that being informed is 'foremost among the responsibilities conferred by pregnancy' (Browner and Press 1997 p117). In such a context, seeking information is seen as an acceptable and, indeed, desirable form of behaviour. Pregnant women's stories of seeking or not seeking information have been found to fulfill the discursive function of presenting the speaker as a 'good mother', someone who is pro-active, connected, attentive to her environment, alert to unexpected possibilities, and receptive to appropriate forms of information (McKenzie 2003a). 
Information seeking in multiple pregnancy/9

Recent research has shown that, for many women, breast-feeding is seen as a similarly integral component of 'good mothering' (Stearns 1999, Schmied et al 2001, Wall 2001). Murphy (1999, 2000) observes that, in neoliberal societies, the 'good mother' is one who maximises physical \& psychological outcomes for her child, regardless of personal cost. Schmied et al (2001) argue that the breast-is-best discourse can lead professionals to breast-feeding-centred rather than woman-centred practice. Women therefore make, display, and defend their baby-feeding decisions within a context in which deciding not to breast feed or abandoning breast-feeding sooner than expert advice recommends can threaten their identities as good mothers (Hausman 2003).

When the imperative of seeking information during pregnancy is combined with the breast-isbest discourse, it is not surprising that many participants told stories of seeking baby-feeding information as though this practice were mandatory. The following passage demonstrates how Jacquie described her reasons for seeking information about breast-feeding:

I guess the biggest concern for me is breast-feeding. So I want to look more into it, get more information, be more educated on it? And then it's easier to make a decision and then, you know, at least if it doesn't work then I say well I've done everything that I could, you know? Not, just going to the hospital and say, 'Oh I'm going to do this,' and having no education or just, no knowledge of what to do and just expect the nurse to show me what to do and, 'Oh well it didn't work for me.' 'Well, you didn't give it a chance really either,' you know?

This account both represents Jacquie as a pro-active planner and shows how antenatal 
Information seeking in multiple pregnancy/10

information-seeking contributes to her efforts to do 'everything I could' to achieve, or at least attempt, successful breast-feeding. Doing 'everything I could' to find information could have negative outcomes, as Rachel described:

I get all uptight about it, cause I think, I guess you kind of want to have, and of course your doctor's telling you, 'Learn as much as you can beforehand. Too much information, there's no such thing. Like, go to the breast-feeding class and go,' like, she said 'That's great. Like, the more information you have, the better.' So then I feel like I should be reading, so I read and stuff but then that really overwhelms me sometimes.

Even Barbara, who expressed her ambivalence about breast-feeding, indicated that it was necessary to find out about breast-feeding 'just in case.'

Barbara: I have been the kind of person who that I've said, 'Oh. Breast-feeding. Forget it. It's not for me.' Um, and to a certain extent I'm still like that.... So I don't even know if I'm going to breast feed or not.

Researcher: Okay. And is this something that you, are, feeling like you have to make a decision about now? Or

Barbara: Nope. No. And in fact um, we've signed up for the prenatal classes and, one of the classes, one of the extra classes is on breast-feeding. And we've signed up for that. Just because I want as much information as I can get, in case I decide to do it.

These pregnant women clearly represent seeking information about baby-feeding, and breast- 
Information seeking in multiple pregnancy/11

feeding in particular, as part of the work that they must do in preparing for motherhood, and describe breast-feeding as an appropriate subject for research. In addition, these accounts demonstrate all three to be willing to 'give breast-feeding a chance'; all are therefore prepared to recognise and accept, at least for the moment, breast-feeding as at least potentially desirable. However, Karen raised the question of how and whether breast-feeding and good mothering are different with multiple birth children: 'I'm concerned about how do you deal with two babies at once? ... Can you breast feed two of them for real, not just in books? [laughs] Can it really be done?' The fact that a woman is carrying twins adds complexity to the discursive construction of good mothering. Participants used the two interpretative repertoires in various ways to negotiate this complexity.

All participants used Repertoire 1, which holds that there is a fundamental distinction between twin pregnancy, birth, and parenting and the singleton experience. This repertoire had two facets. First, it posited a significant difference between feeding and caring for twins and feeding and caring for a single baby. Irene described how a friend modified breast-feeding advice: “"While you're breast-feeding your baby, pump the other breast." Then she went, "Oh. I guess that's not going to work for you." [laughs] You know, she, they kind of make little qualifying statements at the end.'

Second, this repertoire highlighted the common needs and experiences of mothers of twins, regardless of their background or situation. If multiple pregnancy and parenting are accepted as distinct, the fact that all mothers of twins share this distinctiveness allowed participants to 
Information seeking in multiple pregnancy/12

describe an immediate and automatic kinship with other mothers of twins, even those they had never met. Karen, who had just attended her first meeting of a multiple parent support group, said 'there's a sense that we're different,' and that 'even though there was one woman there with triplets, I felt closer to her than to, someone who just had one [baby].'

The two facets of this repertoire have important implications for the information needs women described. Many identified twin-specific concerns about baby-feeding, including issues such as the increased risk of prematurity associated with twins and the ability to produce sufficient milk supply ('That's a question I ask myself uh, could I breast feed both of them? Maybe my body will not be able to produce enough milk for them' --Amina). In addition, several women expressed concern about feeding and caring for two infants rather than one, including the logistics of holding and feeding two when a partner was absent ('What if they're both hungry at the same time and what if there's only me there? Because, if my boyfriend's there then he can bottle feed one while I breast feed the other' --Erica); feeding babies separately or together and the degree to which demand feeding is possible ('I'm worried about one getting up, and then you just nurse them and feed them and then you fall asleep and then the other one's getting up, and then it's like you'd be so tired' --Holly); breast-feeding in public, and combining breast and bottle feeding (alternating each baby between breast and bottle).

Participants used Repertoire 2, which insists that each person is unique, to establish a personal stake for themselves and to explain how their particular situation makes them different from other people. First, they described themselves as distinct individuals, not necessarily like other 
Information seeking in multiple pregnancy/13

people in similar situations. Karen described wanting someone to help her answer the question 'Now, can I breast feed? Not, “Can other mothers breast feed twins?" Can I do it?' Christine made it clear that simply having twins would not necessarily make her like other mothers of twins:

That's the first thing a lot of people... they'll ask me about, 'Oh, you can't nurse now, bla bla bla bla.' And I'm like, 'Why not?' You know, and, ah, then you hear stories of people you know that have had twins and like what they did and bla bla bla bla and like, I'm not them, am I? [laughs]

Second, pregnant women used Repertoire 2 when discussing the individuality of their babies. Much advice to parents about raising their twin children focusses on the importance of treating each child as a distinct individual. The task of raising twin children has been described as a balancing act: 'How can we combine equal and fair distribution of resources with our desire to emphasise individuality and meet individual needs?' (Lytton et al 1995 p191). Attachment is constructed as particularly problematic for mothers of multiples; some suggest that human mothers can bond optimally to only one infant at a time (Abbink et al. 1982), while others indicate that mothers develop preferences for one baby over another (e.g., Minde et al. 1990). What to expect when you're expecting, a popular American pregnancy book read widely in Canada and mentioned by 7 of the 19 participants, counsels mothers to 'recognize that the twins have different personalities, needs, and nursing patterns, and don't try to treat them identically. Keep records and make sure that both are fed at each feeding' (Eisenberg et al, p395). It is evident that participants are aware of these concerns and that they see respecting their infants' 
Information seeking in multiple pregnancy/14 differences as a way of demonstrating good multiple mothering. Rachel received advice about switching an infant from one breast to the other part way through a feed: 'Feed 'em on this breast and then go to this breast.' Rachel's response demonstrates how Repertoire 1 and Repertoire 2 can create discursive conflicts for information-seekers. First, Repertoire 1 allows her to exempt herself from this recommendation: 'Well I'm thinking, well if I'm feeding both at the same time, then I don't have to worry about it.' However, Repertoire 2 requires that she make concessions for her infants' individuality: 'But then of course they keep saying that every child's different, every child feeds differently, this one might be a really ravenous eater compared to this one, so then next time you should switch it around and I think, cause then, cause this breast will produce more milk.' Rachel first rejected and then reconfigured advice for mothers of singletons so that it became appropriate for her situation.

This complex discursive interplay of commonality and individuality, information seeking, babyfeeding and good mothering, underlies the ways that participants explained and justified their baby-feeding decisions in conversation. Understanding this interplay can help us understand the ways that women pregnant with twins describe the authority of information sources, the helpfulness of baby-feeding information, and the barriers in getting helpful and authoritative information.

\section{Interpretative repertoires and the authority of baby-feeding information sources}

Potter and Wetherell's framework provides a means of analysing the ways that speakers use interpretative repertoires to build up or undermine the authority of information sources (Potter, 
Information seeking in multiple pregnancy/15

1996). Several writers (Gardner 1995, Browner and Press 1997, Jordan 1997, McKenzie 2003b) suggest that biomedical authoritative knowledge underlies a representation of pregnancy, and particularly multiple pregnancy, as inherently risky. When describing issues related to their pregnancies, participants commonly relied on biomedical authoritative knowledge as a superior way of knowing. When participants talked about their expectations of postpartum life, however, they more often called upon the authority of knowledge acquired through personal lived experience. Experiential knowledge has been identified as relevant for pregnant and breastfeeding women (Schafer et al.1998, Sheehan 1999, Kettler 2000, Vari et al 2000), and for mothers of twins, who may find that advice from, or intended for, mothers of singly-born children does not help them (Glaser 1987, Van der Zalm 1995).

Participants used Repertoire 1 to highlight the authority of information sources whose authority was derived from direct personal experience. Nowhere was this more striking than in descriptions of baby-feeding, and specifically breast-feeding. Rachel questioned her breast feeding class teacher's expertise:

I asked questions about, pumping and, you know and all this kind of stuff and, I mean that, but she's not, she, doesn't know know. I mean, it's easy for her to say, this is how you can feed two but, she's never done it before. It'd be so nice to know someone who, successfully fed twin babies I think. I think that scares me the most.

Studying the use of Repertoire 1 can also show how outsiders' understandings of multiple 
Information seeking in multiple pregnancy/16 parenting can serve discursively to constrain women's baby-feeding options. Christine told how a mother of singleton children responded to her disclosure that she was pregnant with twins:

That was her first question, yeah about the nursing thing, 'How do you nurse two at a time?' or whatever um, 'You're obviously going to be doing bottles' and. Just, and people assume that. You know? They give you tons of bottles and stuff, and like, formula and all those things.

The discursive constraint imposed by 'people's' assumptions was not just a way of speaking, but in fact led to a social and physical constraint as these assumptions directed the kind of behaviour and support provided to Christine - offsetting costs by giving bottles and formula as gifts, for example, rather than providing social and material support for breast-feeding.

In contrast, a participant could use Repertoire 2 to emphasise the uniqueness of her own situation and thereby effectively dismiss the authority of any source claiming to be objective and universal. Participants 'drew from a range of scripts' (McKenzie 2003b) selectively to accept or reject other people's advice or experience as applicable for their own situation. Barbara provides an example:

I've had people say, 'Well, my friend,' or, 'My sister,' and, and basically they've said, one said, 'Well, they tried it but it didn't work, so she went to bottles.' And, and then uh, 'She tried bottles but that wasn't working so she breastfed but she breastfed them separate and she could only do it for two weeks and-.' Um, so, but, again it's, just personal opinion because it, could have been that, um, not that the breast-feeding didn't work, but maybe she just wasn't comfortable with it or 
Information seeking in multiple pregnancy/17

the babies weren't comfortable with it. So, I just, you know, I just kind of take it in and, I filter what I think I need and what I don't need.

Participants did not, therefore, describe an information source as inherently authoritative or suspect, but constructed complex accounts of the various ways that information sources might be authoritative with respect to the multiple mothering experience in general, or to their own lives in particular.

\section{Helpful and unhelpful information}

Participants described helpfulness as a factor independent of authoritativeness: a nonauthoritative source could provide helpful information. Gayle's friends with infants lacked experiential authority, and she could not 'ask them questions about twins cause they haven't had them. And they don't understand.' These friends could be helpful, however, in the very recognition of their limitations. Gayle continued: 'But they also recognise that. That they don't understand. And I've had some of them say, "Look, I have a girlfriend who had twins, this is her phone number."' The friends accepted multiple parenting as distinctive-in effect, accepting the legitimacy of Repertoire 1-which allowed them to be helpful by providing both support and a referral to an authoritative source.

Helpful baby-feeding information sources also accepted the validity of Repertoire 2, by acknowledging each woman's right to make her own decisions and supporting whatever she believed she should or could do. Stacy 'read about people who breast-feeding was no problem so 
Information seeking in multiple pregnancy/18

that was encouraging.' Trudy described helpful information sources who provided both breastand bottle-feeding information from their own experiences and did so without making judgements about Trudy's potential feeding choices.

Both of them breastfed for two months and said they could have probably gone further, but chose to bottle feed and what I thought was nice was, they didn't say, 'you shouldn't breastfeed,' they said, 'Whatever choice you make, you have to be comfortable with it, and don't let anybody push you either way. However you do it. Just make sure you're comfortable with it and the sanity of the family is,' you know, sort of thing. And I thought, well, that was good. And they gave me techniques on how they bottle fed or how they breast fed, and so I was getting a little more information that way.

Helpfulness, then, is associated with three factors: acceptance of multiple parenting as placing additional and distinct demands on mothers, respect for the pregnant woman's ability to choose the most appropriate course of action, and an expression of confidence in her ability to succeed in her chosen baby-feeding method(s).

\section{Barriers to information seeking}

Participants' desire for experiential information sources and the relative rarity of multiple pregnancy meant that connections with other mothers of twins were both very important and very hard to come by. Participants described seeking out previously unknown individuals or groups in an effort to connect with other parents of twins when none were available within their own 
Information seeking in multiple pregnancy/19

circle. The desire for twin-specific information also resulted in barriers relating to antenatal classes. All of the women who took general antenatal classes or antenatal breast-feeding classes reported being the only one in the class pregnant with multiples. On the one hand, this meant that a participant might see the general advice as irrelevant for her, as Donna did: 'They're covering [breast-feeding] a little bit in the prenatal class. We've just started those. But everyone in the class is having one baby, so I'm sure it's not going to apply easily to me.' On the other hand, women described being reticent to ask the teacher to cover multiple birth issues when they were the only ones in the class with those concerns. Rachel noted 'I said, "I know that probably everyone, everyone else was expecting one but" I said, “can you cover twins a little bit for me"?'

\section{CONCLUSIONS \& IMPLICATIONS FOR PRACTICE}

Understanding and respecting the discursive constructions of pregnancy and mothering and appreciating the relationships of these interpretative repertoires to the ways that pregnant women describe the helpfulness and authoritativeness of baby-feeding information can allow professionals to provide more sensitive support for women's individual needs and understandings. The findings of this study suggest several specific implications for antenatal education and postpartum support for mothers of twins. More generally, an understanding of the ways pregnant women describe and justify their baby-feeding decisions may provide the first steps to what Schmied et al (2001) describe as woman-centred practice, 'the promotion of breast feeding that encompasses the range of perspectives held by women.' 
Information seeking in multiple pregnancy/20

Professionals working with an understanding of Repertoire 1, which emphasises the distinctiveness of twin pregnancy and parenting, could provide the most responsive service by recognising that mothers of multiples may perceive different needs than mothers of singletons. Several of my participants viewed pacifier use (for example, to comfort one crying child while attending to the needs of another) and the option to combine breast- and formula-feeding (for example, alternating each baby from breast to bottle) to be necessary tools in coping with two infants. They reported receiving inconsistent advice, often geared for mothers of singletons, about the risk of nipple confusion, which left them confused and feeling both that their needs were not understood and that their commitment to breast-feeding was called into question.

Professionals serving women pregnant with multiples might consider seeking partnerships with peer support organisations to provide the most effective complementary baby-feeding information services. Professionals who are not themselves parents of twins could maximise their helpfulness by acknowledging the limits of their experiential expertise and making efforts to refer women to experiential sources. For example, a class could be designed specifically for women pregnant with multiples (for an example, see Watson-Blasioli 2001). Such a class could be taught in a way that values both biomedical and experiential forms of authority, for example, by employing an instructor with personal experience caring for infant multiples, or an instructor with the support of (and potentially, guest speakers from) a local multiple birth parenting association. An antenatal multiple pregnancy class could provide pregnant women and their partners with an environment in which they do not feel constrained to ask about the issues that concern them, and in which they have the opportunity to meet others in the same situation, with 
Information seeking in multiple pregnancy/21

whom they may build postpartum peer support networks.

An understanding of Repertoire 2, which emphasises individual differences, suggests that the most helpful advice on baby-feeding might respect the individual woman's right to make her own decision, and the most helpful class or information session would invite pregnant women to talk about how mothering and feeding twins will fit into their individual lives. In addition, pregnant women have been cautioned that good multiple mothering requires working to treat their multiple-birth children as individuals. Sensitive professionals will recognise the pitfalls of uncritically recommending 'one size fits all babies' solutions, and will understand that there are real conflicts between the perceived need to give each infant individual attention and meet his or her needs separately, and the physical limitations of the human body. Nowhere is this clearer than in the definition of 'demand feeding' with multiples and in the question of whether to breast feed twins separately or together, both issues on which participants reported receiving conflicting advice.

In some ways, the diagnosis of a multiple pregnancy frees women from the confines of rigid definitions of 'good mothering,' because what is seen as desirable with one infant may be understood as undesirable or impossible with two or more. On the other hand, women committed to breast-feeding may find that the diagnosis of multiple pregnancy brings with it conflicting discourses that make it very difficult to decide what is best. A sensitivity to the interpretative repertoires used by pregnant women can assist professionals in supporting the antenatal search for baby-feeding information and can help them to avoid imposing inappropriate 
Information seeking in multiple pregnancy/22

models of mothering on the women they serve. 
Information seeking in multiple pregnancy/23

\title{
REFERENCES
}

Aaronson LS, Pfoutz CM, Mural SK. 1988. Seeking information: where do pregnant women go? Health education quarterly. 5:335-345.

\author{
Abbink C., Dorsel S, Flores JE, et al. 1982. Bonding as perceived by mothers of twins. \\ Pediatric nursing 8:411-13.
}

Auer C, Gromada KK. 1998. A case report of breastfeeding quadruplets: factors perceived as affecting breastfeeding. Journal of human lactation. 14:135-41.

Beck, CT. 2002a. Releasing the pause button: mothering twins during the first year of life. Qualitative health research. 12:593-608.

Beck, CT. 2002b. Mothering multiples: a meta-synthesis of qualitative research. MCN, American journal of maternal-child nursing. 27:214-221.

Blondel B, Kaminski M. 2002. Trends in the occurrence, determinants, and consequences of multiple births. Seminars in perinatology. 26:239-49.

Bowers NA. 1998. The multiple birth explosion: implications for nursing practice. JOGNN: Journal of obstetrical, gynecologic and neonatal nursing. 27:302-310. 
Information seeking in multiple pregnancy/24

Britton C. 1998. Clinical issues. The influence of antenatal information on breastfeeding experiences. British journal of midwifery. 6:312-5.

Browner CH, Press N. 1997. The production of authoritative knowledge in American prenatal care. In: Davis-Floyd RE, Sargent CF (eds) Childbirth and authoritative knowledge: cross-cultural perspectives. University of California Press, Berkeley, California, USA:113-131.

Chezem J , Friesen C, Clark H. 2001. Sources of infant feeding information used by pregnant women. Journal of perinatal education. 10:20-6.

Dennis C , Hodnett E, Gallop R et al. 2002. The effect of peer support on breast-feeding duration among primiparous women: a randomized controlled trial. CMAJ: Canadian Medical Association journal. 166:21-8.

Earle S. 2000. Why some women do not breast feed: bottle feeding and fathers' role. Midwifery. 16:323-30.

Eisenberg A, Murkoff HE, Hathaway SE. 1996. What to expect when you're expecting. 2nd ed. Workman Publishing, New York.

Erlandson, DA, Harris EL, Skipper BL, Allen SD. 1993. Doing naturalistic inquiry: a guide to methods. Newbury Park, California: Sage. 
Information seeking in multiple pregnancy/25

Freda MC, Andersen HF, Damus K et al. 1993. What pregnant women want to know. JOGNN: Journal of obstetrical, gynecologic and neonatal nursing. 22:237-44.

Gardner CB. 1995. Learning for two: a study of the rhetoric of pregnancy practices. Perspectives on social problems. 7:29-51.

Glaser BG., Strauss AL. 1967. The discovery of grounded theory: strategies for qualitative research. Chicago: Aldine Publishing Co.

Glaser K. 1987. A comparative study of social support for new mothers of twins. In: Boukydis CFZ (ed) Research on support for parents and infants in the postnatal period. Ablex, Norwood, New Jersey USA:41-60.

Gromada KK, Spangler AK. 1998. Breastfeeding twins and higher-order multiples. JOGNN: Journal of obstetrical, gynecologic and neonatal nursing. 27:441-9.

Hattori R, Hattori H. 1999. Breastfeeding twins: guidelines for success. Birth. 26:37-42.

Hausman BL. 2003. Mother's milk: breastfeeding controversies in American culture. Routledge, New York.

Hoddinott P, Pill R. 2000. A qualitative study of women's views about how health 
Information seeking in multiple pregnancy/26

professionals communicate about infant feeding. Health expectations. 3:224-33.

Howard CR, Schaffer SJ, Lawrence RA. 1997. Attitudes, practices, and recommendations by obstetricians about infant feeding. Birth. 24:240-6.

Izatt SD. 1997. Breastfeeding counseling by health care providers. Journal of human lactation. 13:109-13.

Jordan B. 1997. Authoritative knowledge and its construction. In: Davis-Floyd RE, Sargent CF (eds) Childbirth and Authoritative Knowledge: Cross-Cultural Perspectives. University of California Press, Berkeley, California, USA:55-79.

Kettler, Suzanne K. 2000. Preparing for motherhood: authoritative knowledge and the undercurrents of shared experience in two childbirth education courses in Cagliari, Italy. Medical anthropology quarterly 14: 138-58.

Launslager D. 1995. Research study into the prenatal needs of families expecting a multiple birth. Double Feature. Summer:17-19.

Lincoln YS, Guba EG. 1985. Naturalistic inquiry. Sage, Newbury Park, California USA.

Lowe N. 1998. Breastfeeding information and support services offered by Melbourne 
hospitals in antenatal classes. Breastfeeding review. 6:23-8.

Lytton H, Singh JK, Gallagher L. 1995. Parenting twins. In: Bornstein MH, (ed) Handbook of Parenting. Volume 1: Children and parenting:185-208. Lawrence Erlbaum Associates, Mahwah, New Jersey, USA.

Malmstrom PM, Biale R. 1990. An agenda for meeting the special needs of multiple birth families. Acta geneticae medicae et gemellologiae. 39:507-514.

Mariano C, Hickey R. 1998. Multiple pregnancy, multiple needs. The Canadian nurse. 94:26-30.

McKenzie PJ. 2003a. Connecting with information sources: information seeking as discursive action. New review of information behaviour research. 3:161-174.

McKenzie PJ. 2003b. Justifying cognitive authority decisions: discursive strategies of information seekers. Library quarterly. 73:261-288.

Minde K, Corter C, Goldberg S et al. 1990. Maternal preference between premature twins up to age four. Journal of the American Academy of Child and Adolescent Psychiatry 29:367-75.

Moxley S, Haddon LP. 1999. Focal point on breastfeeding. Teaching breastfeeding to 
Information seeking in multiple pregnancy/28

parents expecting multiple births. International journal of childbirth education. 14:22-7.

Murphy E. 1999. 'Breast is best': infant feeding decisions and maternal deviance. Sociology of health and illness. 21:187-208.

Murphy E. 2000. Risk, responsibility, and rhetoric in infant feeding. Journal of contemporary ethnography. 29:291-325.

Nys K, Colpin H., De Munter A. et al. 1998. Feelings and the need for information and counselling of expectant parents of twins. Twin Research. 1:142-149.

Potter J. 1996. Representing reality: discourse, rhetoric and social construction. Sage, Thousand Oaks, California.

Potter J, Wetherell M. 1987. Discourse and social psychology; beyond attitudes and behaviour. Sage, London.

Rajan L. 1993. The contribution of professional support, information and consistent correct advice to successful breast feeding. Midwifery. 9:197-209.

Schafer E, Vogel MK, Viegas S et al. 1998. Volunteer peer counselors increase breastfeeding duration among rural low-income women. Birth. 25:101-6. 
Information seeking in multiple pregnancy/29

Schmied V, Sheehan A, Barclay L. 2001. Contemporary breast-feeding policy and practice: implications for midwives. Midwifery. 17:44-54.

Seidel, J. 1998. The Ethnograph 5.0. Ver. 5.0. Qualis Research, Salt Lake City, UT.

Sheehan A. 1999. A comparison of two methods of antenatal breast-feeding education. Midwifery. 15:274-282.

Sheehan A, Schmied V, Cooke M. 2003. Australian women's stories of their babyfeeding decisions in pregnancy. Midwifery 19:259-266.

Sheehan D. Krueger P. Watt. Et al. 2001. The Ontario Mother and Infant Survey: breastfeeding outcomes. Journal of human lactation. 17:211-9.

Statistics Canada, Health Statistics Division. 2001. Births. Shelf tables. Statistics Canada, Health Statistics Division, Ottawa.

Stearns CA. 1999. Breastfeeding and the good maternal body. Gender \& society. 13:308325.

Strauss A., Corbin J. 1990. Basics of qualitative research; grounded theory procedures and techniques. Newbury Park, CA: Sage. 
Information seeking in multiple pregnancy/30

Thorpe K, Greenwood R, Goodenough T. 1995. Does a twin pregnancy have a greater impact on physical and emotional well-being than a singleton pregnancy? Birth. 22:148-52.

Van der Zalm JE. 1995. Accommodating a twin pregnancy: maternal processes. Acta geneticae medicae et gemellelogiae. 44:117-133.

Vari PM, Camburn J, Henly SJ. 2000. Professionally mediated peer support and early breastfeeding success. Journal of perinatal education. 9:22-30.

Wall G. 2001. Moral constructions of motherhood in breastfeeding discourse. Gender \& society. 15:592-610.

Watson-Blasioli J. 2000. Feedback analysis of a multiple birth prenatal education program. International journal of childbirth education. 15:14-9.

Wetherell, M., Potter, J. 1992. Mapping the language of racism: discourse and the legitimation of exploitation. New York: Columbia University Press. 